\title{
TRAJETÓRIAS GEOGRÁFICAS DO PIONEIRO ANDRÉ ANTÔNIO MAGGI NA ABERTURA DA FRONTEIRA DO OESTE PARANAENSE
}

\author{
Carlos Alberto Franco da Silva* \\ Universidade Federal Fluminense
}

A partir da Revolução de 1930, Getúlio Vargas iniciou sua doutrina de nacionalizar e ocupar a fronteira guarani dos Estados do Paraná e de Santa Catarina, região fronteiriça com Paraguai e Argentina, através de um projeto geopolítico nacional chamado de "a marcha para o oeste".

Nesta época, o oeste paranaense era predominantemente ocupado por trabalhadores e proprietários de terras de origem estrangeira. Com a retomada do domínio sobre as terras do oeste paranaense pelo Governo Estadual, Getúlio Vargas propôs uma política de ocupação da área que atendesse aos interesses dos capitalistas e colonizadores do Rio Grande do Sul. De certa forma, a idéia de criar o Território do Iguaçu, em 1943, ratificava o projeto de nacionalização das fronteiras políticas do país, subtraindo do Estado do Paraná o controle sobre parte de suas terras, de modo a abrir caminho à expansão do capital e da colonização gaúcha na região. Além disso, havia ainda um problema geopolítico. A abertura da fronteira do oeste paranaense sob a égide dos gaúchos era uma forma de os grupos econômicos do Rio Grande do Sul se contraporem à hegemonia político-econômica que São Paulo tinha durante a República Velha.

Entretanto, um dos principais problemas enfrentados era a nacionalização da mãode-obra do oeste paranaense, dominada por paraguaios, apesar de na escala local do Município de São Miguel de Iguaçú não ter havido esse problema. Por outro lado, a

\footnotetext{
* Este trabalho contou com a co-autoria do bolsista de iniciação científica Cláudio Francisco Severino, discente do Curso de Graduação em Geografia da UFF e integrante da pesquisa coordenada pelo autor e que deu origem ao texto.
} 
estrutura fundiária era marcada pela presença de grandes latifúndios pertencentes a estrangeiros residentes fora do país.

Apesar da anulação do Território do Iguaçu, em 1947, a estrutura produtiva da região já sofria importantes transformações, sobretudo com a crise do mercado da erva-mate, durante as duas Guerras Mundiais, e com a diminuição das importações argentinas. Cabe apenas ressaltar que em Foz do Iguaçu não houve essa crise, já que a erva mate não era explorada.

De qualquer modo, já nos anos 40, época da política de nacionalização da fronteira guarani, havia sérias dificuldades para os latifúndios de propriedade de estrangeiros se manterem economicamente. Com a decadência do comércio do mate, iniciou-se, portanto, a abertura da fronteira do oeste paranaense através da exploração da madeira de lei promovida por brasileiros, paraguaios e argentinos.

\section{A abertura da fronteira do oeste paranaense com a indústria madeireira}

A política de nacionalização e abertura da fronteira do oeste paranaense se deu com o desenvolvimento da colonização em regime de pequena propriedade, ao longo das margens dos rios. Os latifúndios desapareciam e os colonos, vindos do Paraná, Rio Grande do Sul, Santa Catarina e demais estados, abriam caminho para a emergência de uma estrutura fundiária marcada pela presença do pequeno e médio proprietário.

Apesar da emergência da pequena e média propriedade, a presença de latifúndios era expressa através das empresas colonizadoras. O Estado e seus departamentos de assuntos fundiários determinavam a gleba a ser destinada à colonizadora. Nesse momento, as colonizadoras passavam a controlar milhares de hectares de terra, a fim de revendê-las.

A ocupação produtiva e demográfica ficou a cargo de empresas colonizadoras de origem gaúcha, em sua maioria. A mais importante foi a Industrial Madeireira Colonizadora Rio Paraná S/A, conhecida como Maripá, com sede em Porto Alegre e escritório em Toledo. Um dos acionista era Alfredo Paschoal Ruaro, encarregado do serviço de colonização e arregimentação de homens no Rio Grande do Sul. Na verdade, todos os acionistas da empresa eram gaúchos e orientavam-se pela política da "marcha para o oeste", desencadeada pelo Estado Novo. Logo, o oeste paranaense foi colonizado preferencialmente por colonos oriundos do excesso de mão-de-obra agrícola, detectado nas antigas colônias de imigrantes do Rio Grande do Sul. Além disso, vale ressaltar o intenso processo de fragmentação das terras por herança, devido ao crescimento demográfico nas antigas colônias de imigrantes.

A política de abertura da fronteira estava baseada na idéia da disponibilidade de terras e na interação entre o ambiente natural e o esforço coletivo de pequenos proprietários que viam a ocupação do oeste paranaense como uma válvula de escape para as populações pauperizadas e para agricultores capitalizados das antigas colônias de migrantes de origem européia, ou seja, a nova fronteira significava a abertura de novas possibilidades de ascensão social.

Entretanto, havia grande dificuldade enfrentada pelos primeiros pioneiros. As condições naturais da nova terra eram hostis em face da presença de mosquitos. Muitos 
colonos, recrutados para trabalhar na derrubada das matas, construir casas e estradas e derrubar madeira, não suportaram o ecossistema local e abandonaram a região. Dessa forma, o trabalho mais pesado - derrubada da mata para produção de madeira - ficou a cargo dos paraguaios. Percebe-se, portanto, que é preciso relativizar o papel do ecossistema no deslocamento de populações para a região.

Nesse momento de abertura da fronteira agrícola, mais importante do que colonizar era promover a exploração da madeira. Antes de vender a terra ao colono, retirava-se a madeira para a exportação em toros através do rio Paraná.

No final da década de 1940, importantes mudanças da estrutura administrativa da Maripá fizeram com que Alfredo Paschoal Ruaro desempenhasse a mesma função numa outra firma colonizadora, chamada Pinho e Terras Ltda. No ano de 1948, a Colonizadora Gaúcha Ltda, empresa organizada pela Pinho e Terras Ltda, dos empresários Luiz e Alberto Dalcanale e Alfredo Ruaro, iniciou um projeto de fundação de uma nova cidade no oeste paranaense, a partir da compra de uma área que pertencia à Pinho e Terras. Em 1951 foi fundado o povoado de Gaúcha, em homenagem à empresa colonizadora. No início do seu desenvolvimento, o povoado de Gaúcha pertencia ao município de Foz do Iguaçu e a única atividade econômica consistia na extração de madeira de lei e numa agricultura de subsistência.

Muitas famílias gaúchas deixaram o Rio Grande do Sul em busca de terras e trabalho nessa região escassamente povoada. A diretoria da Colonizadora Gaúcha contratou agentes nos municípios gaúchos para fazer o recrutamento de mão-de-obra e de potenciais compradores de terras. João Ghellere era um dos principais corretores de terra da Colonizadora Gaúcha que atuava nos municípios gaúchos. Normalmente, a posse jurídica da terra era legalizada no ato da compra.

Dessa forma, caravanas de colonos com suas famílias começaram a fluir para o povoado de Gaúcha. Os colonos vinham principalmente de Bento Gonçalves, Farroupilha, Guaporé, Criciúma, Missões, São Borja, Santo Angelo, etc. Além da Colonizadora Gaúcha, atuavam na região outras colonizadoras, tais como a Cacique, Laranjeiras Matte e Pinho e Terras. Muitas das terras em poder das colonizadoras eram oriundas da antiga estrada de ferro São Paulo-Rio Grande.

A colonização que se realizou nesta área era, normalmente, espontânea, sem orientação política do Estado, apesar de seu interesse na ocupação do oeste paranaense. Muitas famílias de colonos foram investir e participar da abertura da fronteira.

Uma dessas famílias a se dirigir para o povoado de Gaúcha foi a de André Antônio Maggi, que chegou ao povoado, em 1955.

\section{A importância de André Antônio Maggi nas transformações socioespaciais da fronteira oeste do Paraná}

André A. Maggi, filho de imigrante de origem italiana, nasceu em 30 de janeiro de 1927 , no distrito de Morro Azul, no município de Torres (RS). Até os 25 anos de 
idade morava na casa dos avós. Depois que eles morreram, começou a trabalhar com seu tio, João André Maggi, como peão, limpando terrenos, plantando mandioca. Em 1948 eles abriram um pequeno engenho de farinha de mandioca movido a boi, na fazenda Pontal. Nesta época, André Maggi trabalhava dia e noite arrancando mandioca para a produção de farinha. Além de mandioca, ele plantava banana e cultura de subsistência.

Em 1952 André Maggi se casou com Dona Lúcia. A falta de oportunidades em Torres e a notícia de terras férteis e baratas no oeste paranaense estimularam-no a deixar sua terra em Torres e participar da abertura da fronteira guarani.

De certo modo, sua origem pobre e espírito laborioso funcionavam como impulso à busca de melhores oportunidades. Desse modo, André Maggi levou sua mulher, grávida de mais um filho, Blairo Maggi (atual "rei da soja" brasileira), e suas duas filhas a uma aventura no povoado de Gaúcha. Acompanhando-os, nessa viagem, veio Arnaldo Boff, um grande amigo e atual funcionário de uma de suas fazendas. A viagem para a fronteira foi árdua, mas a esperança de conseguirem terra os movia. $\mathrm{Na}$ realidade, é este movimento por eles desenvolvido que materialmente cria e caracteriza a abertura de uma fronteira.

O caminho até Gaúcha era extremamente longo e cansativo. De Torres até o povoado, a família atravessou serras e campos, ao longo dos três estados sulistas.

Diante da disponibilidade relativa de terras, já que as mesmas estavam sob o controle de empresas colonizadoras, André Maggi alugou um lote no povoado, acompanhando a moderna concepção de movimento pioneiro, conforme Monbeig (1955).

A região passava por fortes transformações, tais como construção de vias de circulação, loteamento de terras rurais e urbanas e a emergência de sistemas de comercialização da madeira. Além disso, o extrativismo da madeira e a agricultura familiar implicavam a destruição das florestas subtropicais e o preparo do solo, demandando um investimento de capital.

Diante da falta de recursos financeiros, nos primeiros de sua chegada à Gaúcha, André Maggi não pôde participar de qualquer tipo de especulação fundiária, que o fizesse se apropriar do valor que a terra possibilitava através da extração e comercialização da madeira. Percebe-se, portanto, que a marcha pioneira no oeste paranaense não se deu através de uma disponibilidade de terras. Na verdade, havia uma disponibilidade relativa de terras, dado o controle do mercado de terras pelas sociedades imobiliárias.

Na verdade, muitos colonos gaúchos foram para o Paraná sem pensar em madeira. No Rio Grande do Sul, os colonos queimavam canafístula e peroba para fazer fogueira e limpar a terra. A madeira não tinha valor para eles. Entretanto, a comercialização da madeira já era significativa no oeste paranaense. Havia algumas grandes serrarias para quem os novos migrantes entregavam a madeira quase gratuitamente, a fim de limpar suas terras.

De acordo com o atual presidente do Sindicato dos Trabalhadores Rurais de São Miguel do Iguaçu, José Rouper, a terra tinha pouco valor. O migrante que possuísse 1 
hectare de terra no Rio Grande do Sul ou em Santa Catarina conseguia comprar 5 hectares em Gaúcha. Após a compra da terra, a família buscava se dedicar à agricultura de subsistência e à criação de porcos. Enfim, os migrantes não se dirigiram ao oeste paranaense pensando em explorar madeira ou na sua industrialização. A marcha dos pioneiros era estimulada pela possibilidade de acesso à terra e à produção de um excedente agrícola que poderia ser comercializado em grandes mercados.

Desse modo, chegando em Gaúcha praticamente descapitalizado e sem poder adquirir terras agricultáveis, André Maggi foi trabalhar na Serraria São Pedro, que era a maior geradora de emprego da região e pertencia à empresa Colonizadora Gaúcha. Durante algum tempo, essa serraria forneceu madeira para a construção da Ponte da Amizade, entre Brasil e Paraguai. Na realidade, cabe ressaltar que as companhias de colonização eram, de fato, madeireiras. A terra era um elemento residual e tinha pouco valor. A extração madeireira comandava a apropriação de valor. A produção atendia o mercado interno regional e também Minas Gerais, São Paulo, Rio de Janeiro e Rio Grande do Sul.

Somente a partir dos anos 60 começou o beneficiamento da madeira. De início, a madeira era comercializada em toras transportadas através dos rios. Só se aproveitava a nata da madeira, o resto era queimado. Com a etapa do beneficiamento, surgiu a produção de assoalho, forro, etc. É nesse momento que ocorreu maior circulação de capital no município. De acordo com Ferdinando Pagot, primeiro prefeito nomeado como interventor, durante o governo militar, São Miguel do Iguaçu chegou a ter mais de 20 serrarias na década de 60 .

No início, as dificuldades junto à madeireira e a falta de recursos para a compra de terras que pudessem melhorar seu padrão de vida fizeram com que André Maggi resolvesse voltar para o Rio Grande do Sul.

De acordo com depoimento do próprio André Maggi, ele possuía uma caminhonete para puxar a madeira que era recolhida das matas. Entretanto, este veículo estava sempre com problemas mecânicos, impedindo André Maggi de ampliar seus recursos monetários. Neste momento, sua mulher, Lúcia Borges, protagonizou um dos episódios mais visionários da saga desta família. Em face dos problemas, Dona Lúcia afirmou que a família não deveria voltar jamais para Torres. Apesar do malogro da experiência inicial, ela acreditava que a família só poderia caminhar para frente e nunca para trás. De certa forma, a personalidade de sua esposa marcou e serviu de base para a história de uma das mais importantes famílias de pioneiros no oeste paranaense. Isso porque ser pioneiro é um estado de espírito que implica um processo de fixação e avanço sobre novas terras, de modo a buscar sempre um melhor padrão de vida.

No povoado, a família morava numa pequena casa de madeira, que chegou a pegar fogo algumas vezes. Depois de 6 meses em Gaúcha, André Maggi foi promovido a gerente da Serraria e recebia $20 \%$ de participação nos lucros. Esse percentual só foi conseguido porque a serraria dava muito prejuízo a seus donos.

De qualquer forma, André Maggi aceitou o desafio. Marcado por um espírito laborial, além do trabalho na serraria, ele trabalhava nos finais de semana, retirando 
madeira das matas para vender. Iniciando o dia às 4 horas da madrugada, caminhava quilômetros a pé até a mata, carregando apenas pão e salame para sua alimentação. Desse modo, com as terras ainda valendo pouco, investiu seu salário e algumas economias na compra de terras, preparando, assim, sua volta à atividade de origem, a agricultura. Logo, depois de 2 anos e meio, André Maggi saiu da Serraria São Pedro.

É nesse momento que ele comprou a fazenda São Vicente de uma firma de São Paulo, a Serraria Cacique, e se afastou da Serraria São Pedro. Entretanto, antes de comprar a fazenda André Maggi já havia comprado três chácaras que foram vendidas para João Ghellere. Há relatos de que André Maggi também trabalhou como corretor de terras em Torres. Após comprar uma caminhonete que pertencia a João Ghellere, ele realizou várias viagens a Torres, vendendo lotes de terras.

A partir da compra da Fazenda São Vicente que possuía uma pequena serraria, o padrão de vida da família Maggi melhorou após a construção de uma casa de dois andares cuja parte inferior era uma mercearia aberta em sociedade com um amigo. $\mathrm{O}$ abastecimento da mercearia era feito através da compra de alimentos e de outros produtos oriundos da Argentina e Paraguai. Esta era a única mercearia do povoado naquela época.

Nesta propriedade viviam as famílias do Sr. André e a do pai do Sr. Altair Fabris, que viria a ser um dos mais importantes funcionários da empresa. Mesmo com a compra da fazenda São Vicente, a família continuou morando no povoado Gaúcha, numa casa que era considerada a melhor da redondeza. Entretanto, apesar da sensível ascensão social, a casa do Sr. André vivia sempre cheia de pessoas de todos os níveis de renda, isto é, não havia uma atmosfera de discriminação social.

A presença de pessoas influentes na política e na economia local na casa de André Maggi era uma estratégia dele estar perto de pessoas que pudessem ajudá-lo a melhorar de vida. Ao participar desse circuito social, André Maggi acabou se tornando um dos líderes políticos da emancipação de Gaúcha do município de Foz de Iguaçu.

Isso porque a presença de gaúchos e catarinenses em Gaúcha acabou por criar um sentimento de pertencimento àquela terra, a partir da identidade social e cultural dos habitantes. A distância de $45 \mathrm{Km}$ de Foz de Iguaçu impedia o acesso a serviços básicos à população. Além disso, havia um clima de descontentamento com a administração municipal em face da carência de serviços de cartório, registro civil, estradas, etc. $\mathrm{Na}$ verdade, os agricultores de Gaúcha sentiam-se prejudicados por elegerem políticos de Foz do Iguaçu que não resolviam os problemas do distrito. Unindo-se aos principais líderes do povoado e da empresa Colonizadora Gaúcha, André Maggi projetou-se na política de emancipação.

A luta pela emancipação de Gaúcha foi ainda favorecida pela política do Estado Nacional de promover maior fragmentação territorial dos municípios do oeste paranaense, enquanto uma estratégia geopolítica de ocupação política e econômica dessa região fronteiriça do país. 
$\mathrm{Na}$ verdade, não houve uma repressão ao movimento de emancipação. O próprio município de Foz de Iguaçu estimulava o desmembramento, de modo a se dedicar a um controle sobre a extração da madeira por argentinos.

Desse modo, em 29 de Janeiro de 1961, foi criado o Município de São Miguel do Iguaçu e o primeiro prefeito foi Abel Bez Batti. André Maggi foi eleito vereador pelo PTB (Partido Trabalhista Brasileiro), com o maior número de votos e, logo em seguida promovido a Presidente da Câmara Municipal.

De um modo geral, André Maggi era um líder político que administrava a cidade através de amigos e pessoas influentes. O segundo prefeito da cidade foi seu primo, Nadir Maggi. Político assumidamente de direita, durante o Estado Militar, André Maggi se voltou para a diretoria da ARENA, partido oficial do Governo Federal. Nessa época, São Miguel do Iguaçu localizava-se em área de segurança nacional. Logo, em 1968, época do AI-5, foi indicado um interventor para o município, Ferdinando Felice Pagot, amigo de André Maggi.

A administração de Ferdinando Pagot foi beneficiada pelo fato de São Miguel do Iguaçu ser área de segurança nacional. Através de recursos do Estado, abriu escolas, forneceu abastecimento gratuito de água e desapropriou terras para assentamento de colonos que estavam na área do Parque Nacional do Iguaçu.

Muitas das reuniões do prefeito com membros do Batalhão de Segurança e da Marinha, a fim de pôr em prática as determinações do governo militar, eram acompanhadas da presença de André Maggi.

De acordo com amigos pessoais, a participação de André Maggi na política era de cunho idealista. Não havia interesse em se beneficiar economicamente do poder político, apesar de que o político e o lado empresarial estiveram sempre juntos, ao longo de sua história. Na realidade, por mais que o lado empresarial e o político pudessem parecer separados, a dinâmica social da família Maggi integrava o econômico e o político como um processo único e indivisível.

Durante a atmosfera política conflituosa imposta pela Ditadura Militar, a rotina de constante trabalho, durante toda a semana, e a extrema economia domiciliar possibilitaram a André Maggi desenvolver a Serraria São Vicente, em 1968, chamada vulgarmente do tipo pica-pau. Como o nível de investimento para entrar na extração de madeira era baixo, André Maggi não encontrou grandes dificuldades para expandir seu próprio negócio.

Em uma outra parte da Fazenda São Vicente, onde estava sendo aberta a serraria, o café foi introduzido como lavoura comercial. Porém, foi um fracasso e erradicado devido em grande parte às geadas que atingiam a região e o resto do Estado do Paraná. Com seu recuo, instalou-se a pecuária.

Apesar da experiência fracassada com o café, o principal negócio da família já era o comércio da madeira. A importância dessa atividade econômica fez com que André Maggi ampliasse as instalações de sua serraria. $\mathrm{O}$ fornecimento de madeira era proporcionado pela compra de áreas de matas em terras devolutas e de reservas de matas em propriedades de outros colonos. A mão-de-obra contratada para retirada da madei- 
ra e de seu transporte até a serraria era predominantemente de paraguaios, apesar da presença de trabalhadores brasileiros, sobretudo gaúchos e catarinenses. Os paraguaios residiam em acampamentos temporários, trabalhando por empreitada e sazonalmente.

Do ponto de vista da cobertura vegetal, a região de São Miguel do Iguaçu não localizava-se num domínio da floresta de Araucária. A madeira extraída provinha de outras espécies: cedro, marfim, peroba, etc. O sucesso do comércio de madeira proporcionava a André Maggi a incorporação de terras através de compra de propriedades de outros colonos endividados ou interessados em investir em outras áreas do país. Além disso, a serraria florescia nos locais em que havia terras em disputas e a possibilidade de alguns camponeses serem retirados. Preocupados em vender as árvores de suas propriedades a baixo preço, sabendo que poderiam perdê-la, os camponeses possibilitaram significativos lucros às pequenas serrarias. Isso porque havia uma grande oferta de madeira num mercado de poucos compradores.

O desenvolvimento das forças produtivas expresso nas melhorias das instalações da serraria, como por exemplo a introdução da serra-fita, era acompanhado pela compra de terras.

De um modo geral, podemos afirmar que o valor da terra era bem menor do que a madeira que ali havia. $\mathrm{O}$ valor da produção de madeira de uma propriedade era aproximadamente o dobro do preço pago pela terra. Tal processo de compra e de concentração de terras significou o domínio de aproximadamente 200 hectares de terras, nas mãos de André Maggi, ou seja, uma grande propriedade para os padrões de distribuição de terras da Região Sul, ocupadas principalmente por colonos de origem européia.

A fim de garantir a reprodução ampliada do seu capital, André Maggi só comprava terra com mata virgem e madeira de lei. Além disso, a propriedade deveria estar localizada próxima à Fazenda São Vicente, em função do preço alto do frete. Após o desmatamento de suas novas terras, iniciava-se o plantio de lavouras, tais como milho, soja, feijão e trigo. A agricultura era uma forma de diversificação e integração de sua estrutura produtiva, bem como parte integrante da característica de um pioneiro.

A fazenda São Vicente era a sede dos negócios da família. A organização territorial da fazenda era marcada pela presença da mata, casa dos peões, serraria, a sede, criação de porcos e gado e uma pequena lavoura de grãos.

Na Fazenda São Vicente a madeira era industrializada e boa parte da produção de milho era destinada para a alimentação dos animais.

A criação de porcos era uma atividade paralela à serraria. A presença de um frigorífico em Medianeira que pertencia a Antônio Paschoal Ruaro, um antigo patrão de André Maggi, permitia a venda de porcos para o abate. A importância da suinocultura se traduzia na melhoria das instalações voltadas ao trato e reprodução dos animais. De qualquer maneira, era a madeira o carro-chefe dos negócios da família e de todo o oeste paranaense.

A importância da extração da madeira no oeste paranaense se traduzia na captação de $80 \%$ dos empregos gerados pela indústria, na década de 50. Além disso, cerca de $60 \%$ 
de todas as empresas não-agrícolas estavam voltadas para o setor madeireiro (CODEPAR, 1964). Na verdade, foi a predominância dessa atividade econômica que colocou a agricultura num segundo plano. Ao lado das grandes companhias madeireiras, havia espaço para a participação de pequenas serrarias, tal como a Serraria São Vicente.

A área de influência da Serraria São Vicente era predominantemente local. Muitos colonos que vendiam suas reservas de mata para o Sr. André Maggi eram os mesmos consumidores de sua produção, já que necessitavam dela para construção de casas, galpões e demais dependências em suas fazendas. O excedente da produção era comercializado para os mercados de Curitiba e São Paulo, sobretudo a partir de 1967, com a abertura da rodovia BR-227, que ligava o oeste paranaense à Curitiba. A construção dessa estrada possuía um caráter não só econômico, mas também geopolítico relativo à segurança nacional.

Cabe ressaltar que, havia uma certa dificuldade de estender o raio de ação da serraria de André Maggi sobre outros municípios do oeste paranaense, visto que a presença de madeira de lei era marcante em várias localidades, tais como Céu Azul, Matelândia, Medianeira e Foz do Iguaçu.

A compra da Fazenda do Índio, que pertencia a paulistas, em 1969, possibilitou um rápido crescimento da Serraria São Vicente. Havia muita madeira de lei na nova propriedade. Com efeito, pôde-se ampliar o mercado para a construção civil nas praças de Curitiba e São Paulo. Além disso, a serraria passou a fornecer madeira para intermediários que exportavam-na para os Estados Unidos. A fim de garantir maior fluidez entre a extração e transporte da madeira, André Maggi comprou duas carretas Scania. Entretanto, o grande salto dos negócios se deu com venda de madeira para a construção de dormente, durante a construção da ferrovia que ligava Ponta Grossa a Apucarana. Nesse momento, a Serraria São Vicente teve o Estado como um dos principais clientes da empresa.

Havia financiamento do Estado para o aumento da produção de madeira. Buscando ampliar sua participação na oferta de madeira, André Maggi pôs sob sua órbita outras serrarias do oeste paranaense, sobretudo de São Miguel de Iguaçu e Medianeira, visto que o Estado só recebia grandes encomendas, retirando, assim, a possibilidade de comercialização direta com as pequenas serrarias. De uma certa forma, grande parte do oeste paranaense estava sob o boom da madeira. O mercado de trabalho da região estava praticamente envolvido com o extrativismo e industrialização da madeira de lei, conforme já assinalamos.

Entretanto, cabe ressaltar que, no final dos anos 60 (1968-1972), o oeste paranaense foi marcado por um rápido ciclo do plantio da hortelã que implicou uma fase de intenso arrendamento da terra pelo preço de $18 \mathrm{~kg}$ de óleo por alqueire. Nesse cenário de especulação, havia a figura dos gatos que arrendavam as terras e repassavam-na aos produtores.

Da hortelã se produzia um óleo extraído da erva, que era beneficiado em alambique. A primeira destilação era feita na lavoura, onde havia os alambiques. 
A fim de participar da febre da hortelã, André Maggi arrendava terras e adquiriu um alambique. A renda proporcionada pelo óleo de hortelã era muito boa. O óleo era utilizado em pneus, combustível de aviões e em muitos setores da indústria química. O principal mercado era o japonês.

A expansão da hortelã ia de Foz do Iguaçu à Matelândia. Cerca de 12 mil famílias plantavam e dedicavam-se ao plantio da erva. Muitos agricultores que vendiam sua madeira lançaram-se à hortelã. Não havia mecanização, o cultivo era exclusivamente manual.

Em face do curto período de duração, depois de quatro anos de trato da lavoura, não havia condições para o replantio. A hortelã só produzia em terra nova, virgem. Em terras já cultivadas com intensa mecanização a hortelã só produzia por um ano. Como a lavoura era de difícil manutenção, tornou-se inviável mantê-la apenas por um ano. Além disso, a lavoura foi atingida por praga, o que inviabilizou e pôs em decadência o ciclo da hortelã. Muitos agricultores abandonaram a hortelã e voltaram-se às atividades tradicionais. Nesse sentido, André Maggi não fugiu à regra geral. Entretanto, a atividade madeireira também já apresentava sinais de esgotamento.

No início dos anos 70, André Maggi vendeu a Serraria em função da decadência do surto de colonização que implicou a diminuição de áreas de matas para extração de madeira. O progressivo povoamento da terra constrangia seriamente as operações das companhias madeireiras, exatamente durante o período da rápida elevação dos preços. Além disso, a construção da hidrelétrica de Itaipu alagou parte das terras disponíveis ao extrativismo. A madeira estava tornando-se cara e era necessário atingir grandes distâncias para obtê-la, aumentando, portanto, o preço do frete. Diante desse cenário, antes que a madeira se esgotasse, ele vendeu a serraria para um grupo de São Paulo, Serraria Samarti, interessado em atender a demanda de madeira para a construção do metrô paulista. Havia cerca de 5000 metros de Ipê e várias máquinas que foram entregues à Samarti.

Ainda nesse período, André Maggi saiu, temporariamente, da política devido a um sentimento de desvalorização pessoal quando da indicação do sucessor de Ferdinando Felice Pagot na prefeitura do município. Entretanto, Ferdinando continuou como seu braço direito na política. Nas eleições de 1972 fez campanha para João Batista de Lima, que foi eleito vereador com o maior número de votos. Hoje, João Batista é um dos funcionários de confiança do Grupo Maggi.

Com a venda da serraria, André Maggi se voltou mais intensamente à agricultura, apesar de nunca tê-la abandonado por completo. Paralelamente ao comércio de madeira, ele foi um dos pioneiros na mecanização da terra. Com a limpeza das terras após o desmatamento através da técnica de enleirar (faziam-se montes com os restos de madeira e tocos), abria-se caminho para a introdução de tratores de esteira, comprados inicialmente em Cascavel (PR). Tais processos ocorriam basicamente na Fazenda São Vicente.

A existência de terras férteis e terreno de origem quaternária e terciária levemente ondulado e o clima subtropical úmido facilitaram a introdução das lavouras comer- 
ciais de soja, milho, feijão e trigo. Para tanto, foi construído um armazém para a estocagem. O financiamento à produção era dado pelo Banco do Brasil, que, em troca, exigia o plantio em curvas de nível. Após uma resistência inicial, André Maggi se tornou um dos maiores defensores desse tipo de política contra a erosão do solo.

Apesar da venda da Serraria, ela foi poucos anos mais tarde comprada do mesmo grupo paulista, que passava por sérias dificuldades financeiras. Todavia, a serraria não serviria mais para a produção de madeira. Ela tornou-se inviável economicamente em face da decadência do boom da madeira na região. Além disso, André Maggi já estava com os pés bem fincados na agricultura.

Na Fazenda São Vicente, em área onde inicialmente se plantou café e em seguida introduziu-se a pecuária, emergiu a lavoura comercial de grãos. Com o recuo da pecuária ampliou-se a produção de grãos e de sementes de soja, milho e trigo. Para tanto, foi construído um armazém graneleiro para sua própria produção. A construção desse armazém foi estratégica. Isso porque as dificuldades de outros produtores de comercializar sua produção na cidade serviram de base para que eles ficassem, cada vez mais, sob a órbita e dependência do armazém do André Maggi. Logo em seguida, foi construído o segundo armazém graneleiro.

A grande estratégia do André Maggi foi se dedicar ao comércio de grãos de soja, que se afirmava como importante lavoura comercial no oeste paranaense. Esse é o segundo grande momento da história econômica de São Miguel do Iguaçu com a abertura da fronteira agrícola após o ciclo da madeira. De 1973 a 1977, a soja apresentou números de desenvolvimento altamente expressivos em São Miguel do Iguaçu. A área plantada aumentou de 28100 ha para 45837. A produção saltou de 50580 toneladas para 122778, conforme dados do IBGE (Censo Agropecuário do Paraná, 1980).

A entrada da soja no oeste paranaense remonta a 1967, quando o plantio para teste foi introduzido. No início plantava-se soja manualmente. Derrubava-se o mato, faziase o plantio e deixava-se fazer uma capoeira para eliminar as madeiras que permaneciam.

Após os testes, constatou-se a rentabilidade e viabilidade econômica da soja. Entretanto, a ocorrência da lagarta da soja em 1973 provocou um susto nos produtores. Utilizavam-se defensivos, tais como BHC e o LVC, que eram muitos tóxicos. Somente com a ajuda da EMATER, a soja começou a se desenvolver.

$\mathrm{Na}$ área da agricultura, os produtores começaram a firmar convênios com a EMATER e o Estado. Fundaram a ACARPA, em 1970, a fim de promover cursos de formação e orientação técnica. Depois, eles partiram para o cooperativismo e convênios com várias entidades ligadas à pesquisa. Os recursos financeiros se dirigiam à Prefeitura e ela investia nos setores básicos ao desenvolvimento da lavoura de grãos. O trabalho maior que a Prefeitura realizava era o da manutenção dos convênios junto à Secretaria da Agricultura do Paraná, EMATER e com o Campo Experimental de Londrina- EMBRAPA. A prefeitura intervia, fazia reuniões, "dias de campo", muitas vezes patrocinados por André Maggi, que começava a se destacar na produção e comercialização de grãos de soja. 
André Maggi fornecia sementes e/ou adiantava dinheiro para que outros agricultores produzissem grãos. A cada saca de sementes fornecida, o produtor devia pagar com duas sacas de grãos de soja, que era, por sua vez, comercializada com grandes grupos do setor alimentício brasileiro, tais como a SANBRA. Emergia, portanto, um mercado futuro para a produção de grãos que teve a figura do André Maggi como um dos pioneiros no país. Os agricultores que se voltavam para a lavoura de soja necessitavam de adubos, sementes e maquinários. André Maggi antecipava o financiamento à produção, captando recursos junto às indústrias, como a CARGIL, e repassava aos produtores, recebendo em troca o pagamento em grãos que eram enviados às grandes empresas do setor de alimentos da época: SANDRA, CARGIL, ANDERSON CLAYTON, entre outras. Na realidade, André Maggi aproveitou as oportunidades de negócios e financiamentos gerados pelo processo de abertura da fronteira agrícola do oeste paranaense, com a lavoura de grãos.

De um modo geral, pode-se definir André Maggi como um pioneiro que examinava o presente, imaginando que o futuro estivesse ali, embutido no presente. Na realidade, cada ato dele era o presente agindo em função do futuro. A ação era presente, mas a aspiração dele era o futuro ${ }^{1}$.

Desse modo, com a expansão da lavoura de soja no país e, sobretudo, no oeste paranaense, André Maggi, além de construir armazéns para comercialização de grãos e produção de sementes, fundou, em 1976, a empresa Sementes Maggi, com capital originário do Banco do Brasil S/A, instalando, na época, a maior unidade de produção de sementes do Estado do Paraná.

A atuação dessa empresa era, de início, ao nível do Município de São Miguel do Iguaçu. A produção de sementes contava com uma rede de produtores cooperados que produziam sementes para a empresa, onde a soja era beneficiada, ensacada e empilhada. Os grãos de soja, obtidos com a troca de sementes por grãos, eram comercializados com grupos industriais de Cascavel e outras cidades do oeste paranaense. De 1976 a 1979, a dinâmica de reprodução ampliada do capital da empresa limitavase ao Paraná, sobretudo o oeste do Estado.

Entretanto, a busca de novas áreas de expansão da lavoura levou André Maggi a uma aventura fracassada na Amazônia, em 1977, aproximadamente. Nessa época, ele não conhecia os ecossistemas do Cerrado e da Amazônia. Não tinha informações técnicas sobre a diferença de produtividade nos dois grandes domínios naturais do país. Ele acreditava que o cerrado era improdutivo para a lavoura devido ao pequeno porte das árvores, enquanto a exuberância da Floresta Equatorial Amazônica sinalizava com altos índices de produtividade da terra.

\footnotetext{
${ }^{1}$ Trecho parafraseado de uma entrevista de Milton Santos ao Jornal Folha de São Paulo, em 07/03/2000, intitulado "Um olhar dissonante", de autoria de Valmir Santos.
} 
De início foram comprados aproximadamente 100 mil hectares de terras em Camutana (AM) e cerca de 2 a 5 mil hectares em Humaitá (AM). Tal compra foi um fiasco, visto que ele comprou terras com título de posse falsificado. Tais terras pertenciam ao Estado. Logo, perdeu todo o dinheiro e abandonou a região. Em Porto Velho (RO) ainda há uma propriedade com cerca de 3000 ha. Durante essa aventura, que durou quase 2 anos, André Maggi contraiu malária e quase morreu.

De qualquer modo, em 1979, a empresa Sementes Maggi já estava preparada para abertura de uma filial no sul do Mato Grosso. Sempre olhando para o futuro e sem medo de arriscar, André Maggi se dirige ao sudeste matogrossense, onde vai desempenhar um importante papel na abertura da fronteira agrícola da Amazônia, sobretudo em áreas de ocorrência de cerrado.

\section{Para não concluir}

A trajetória geográfica de André Antônio Maggi ao longo do processo de abertura da fronteira agrícola do oeste paranaense se constitui num registro da prática socioespacial de um pioneiro enquanto reflexo e condição das transformações na estrutura socioeconômica e política de uma região.

A partir de suas práticas socioespaciais tem-se a oportunidade de verificar as bases sobre as quais surge um dos principais agentes de transformação do espaço agrário brasileiro, não só no oeste paranaense, como também em áreas de cerrado. O sistema de ações e de objetos que caracterizam a emergência do empresário André Maggi faz emergir uma lógica capitalista cuja dinâmica resulta de processos históricos de abertura de fronteira agrícola no país. Isso porque André Maggi, apesar de começar sua trajetória como um pioneiro descapitalizado, vai aos poucos se tornando um latifundiário ao se apropriar de terras de pequenos produtores, durante a fase de domínio da indústria madeireira. Em seguida, ao se consolidar como um importante produtor de soja, traz para sua órbita vários produtores através do processo de comercialização de grãos. Para tanto, toda uma rede de articulações políticas com grupos internacionais e governos municipais e estaduais é acionada, a fim de garantir as bases de seu domínio territorial.

Enfim, é a partir do seu processo de produção socioespacial no oeste paranaense que André Maggi adquiriu as condições materiais para participar da abertura da fronteira do sudeste matogrossense. Mas isso já é uma outra história, i.e., uma outra trajetória geográfica desse empresário do agribusiness que deveremos resgatar. 


\section{TRAJETORIAS GEOGRÁFICAS DO PIONEIRO ANDRÉ ANTÖNIO MAGGI NA}

\section{ABERTURA DA FRONTEIRA DO OESTE PARANAENSE}

Resumo: Este artigo tem como objetivo resgatar a trajetória geográfica do pioneiro André Antônio Maggi, atual presidente do Grupo André Maggi, maior exportador de grãos de soja do país, ao longo do processo de abertura da fronteira agrícola do oeste paranaense.

Palavras-chaves: Pioneiro, Fronteira, Espaço

\section{GEOGRAPHIC TRAJECTORIES OF PIONEER ANDRÉ ANTÔNIO MAGGI IN THE OPENNING OF WEST PARANÁ FRONTIER}

Summary: This issue shows the geographic trajectory of pioneer André Antônio Maggi, president of Group André Maggi, the biggest soya exporter in Brazil, dealing with his participation in the opening of agrarian frontier in the west of Paraná state.

Keywords: Pioneer, Frontier, Space.

\section{BIBLIOGRAFIA}

CODEPAR. Relatório de 1964.

MONBEIG, Pierre (1998). Pioneiros e fazendeiros de São Paulo. São Paulo: Hucitec. WACHOWICZ, Ruy Christovam (1982). Obrageros, mensus e colonos: história do oeste paranaense. Curitiba:Vicentina. 